Research Article

\title{
Guidance, Navigation, and Control for Fixed-Wing UAV
}

\author{
Amber Israr $\mathbb{D},{ }^{1}$ Eman H. Alkhammash $\mathbb{D}^{2},{ }^{2}$ and Myriam Hadjouni $\mathbb{D}^{3}$ \\ ${ }^{1}$ Electronic Engineering Department, Sir Syed University of Engineering \& Technology, Karachi 75300, Pakistan \\ ${ }^{2}$ Department of Computer Science, College of Computers and Information Technology, Taif University, P. O. Box 11099, \\ Taif 21944, Saudi Arabia \\ ${ }^{3}$ Computer Sciences Department, College of Computer and Information Sciences, Princess Nourah bint Abdulrahman University, \\ Riyadh, Saudi Arabia \\ Correspondence should be addressed to Amber Israr; aisrar@ssuet.edu.pk
}

Received 10 September 2021; Accepted 27 September 2021; Published 16 October 2021

Academic Editor: Dao B. Wang

Copyright () 2021 Amber Israr et al. This is an open access article distributed under the Creative Commons Attribution License, which permits unrestricted use, distribution, and reproduction in any medium, provided the original work is properly cited.

The purpose of this paper is to develop a fixed-wing aircraft that has the abilities of both vertical take-off (VTOL) and a fixed-wing aircraft. To achieve this goal, a prototype of a fixed-wing gyroplane with two propellers is developed and a rotor can maneuver like a drone and also has the ability of vertical take-off and landing similar to a helicopter. This study provides guidance, navigation, and control algorithm for the gyrocopter. Firstly, this study describes the dynamics of the fixed-wing aircraft and its control inputs, i.e., throttle, blade pitch, and thrust vectors. Secondly, the inflow velocity, the forces acting on the rotor blade, and the factors affecting the rotor speed are analyzed. Afterward, the mathematical models of the rotor, dual engines, wings, and vertical and horizontal tails are presented. Later, the flight control strategy using a global processing system (GPS) module is designed. The parameters that are examined are attitude, speed, altitude, turn, and take-off control. Lastly, hardware in the loop (HWIL) based simulations proves the effectiveness and robustness of the navigation guidance and control mechanism. The simulations confirm that the proposed novel mechanism is robust and satisfies mission requirements. The gyrocopter remains stable during the whole flight and maneuvers the designated path efficiently.

\section{Introduction}

Aerial vehicles have many usages in the academic, civilian, and military areas due to significant progress made in information technology, solid-state devices (SSD), and battery technologies [1]. By installing cameras on aircraft, its applications can even expand to technical data collection, reconnaissance and surveillance, satellite farming, forest fire detection, and geographical surveys [2]. The above-mentioned uses of flying aircraft are only a brief outline of its possible applications. Recent research in aviation has produced a vast demand for customized aircraft that can perform particular tasks and are significantly more robust than older aircraft models. Also considering the requirement of autonomous air vehicles, the research area is substantially expanded, necessitating the use of navigation tools and complex control mechanisms [3].

One type of aircraft is a fixed-wing flying machine. It is an air vehicle that flies with the help of wings. The shape of the wings and the forward airspeed of the aircraft helps the wings produce lift. Fixed-wing is different from rotary-wing air vehicles, in which the wings form a rotor attached to a circling shaft [4]. The wings of fixed-wing air vehicles do not have to be rigid. Researchers often compare fixed-wing aircraft with helicopters. Although they have some similarities, they differ as well. The engine drives a helicopter; its control transmission system structure is also very complex. Helicopters have the ability of vertical take-off and landing [5] whereas fixed-wing aircraft can hover but it cannot take off vertically [6]. It must take off the ground. Fixed-wing aircraft cost less than helicopters, so they are suitable for hobbyist purposes, too [4]. Figure 1 shows an example of a fixed-wing UAV.

The development of unmanned aircraft started as far back as the early twentieth century [7]. In 1923, the test flight of the C-4 rotor aircraft was successful, also known as the "windmill aircraft" [8]. In 1929, a new type of PCA-2 


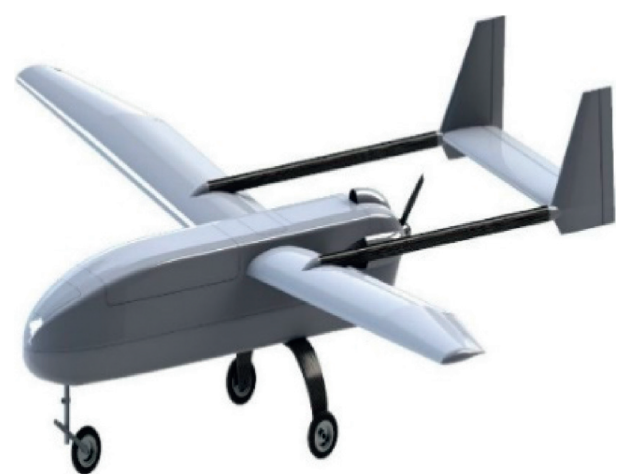

Figure 1: Fixed-wing UAV.

rotary-wing aircraft appeared, the first rotary-wing aircraft to obtain a flight license [9]. In 1934, using direct control rotor technology, the C-30 rotor aircraft achieved jump takeoff [10]. In 1939, the VS-300 helicopter with the characteristics of a modern helicopter successfully flew [11]. Since then, the helicopter has developed rapidly, and the upsurge in research in helicopters has almost replaced the rotor aircraft. In 1953, Igor Benson's B-8M rotorcraft was successfully tested [12]. It attracted the attention of many enthusiasts due to its simple structure, convenient use, and low cost. In 1955, McDonnell xv-1 and Fairey Rotodyne highspeed rotor aircraft was successfully manufactured [13]. The flying principle is that the engine drives the rotor to take off vertically, and then, the engine of the fuselage pushes it forward. Finally, the engine with the tip of the rotor closed provides the lift through the rotor rotation. In recent years, Carter Copter and Hawk-4 high-speed rotary wings made in the United States have appeared [14]. From the point of view of their shape and structure, they are composed of the rotor disc and fixed-wing vertical tail and flat tail related control mechanism, which synthesizes the advantages of rotor aircraft and fixed-wing aircraft [15]. There is also some development in the military transport aircraft market.

To develop a control strategy for the fixed-wing aircraft, we first consider individual techniques like PID, LQR, or using a neural network. Control systems are generally divided into two categories, open- and closed-loop systems. Proportional-Integral-Derivative (PID) controller is a closed-loop control system. In the PID controller, a feedback signal is used which senses the plant output and transmits it back so that the system is able to adjust appropriately. Neural networks are powerful tools that are capable of approximating numerous linear and nonlinear functions. In many cases, these networks can adjust to varying input-output relations.

After careful consideration, we came to the conclusion that these techniques alone are not enough. We can complement them and reduce their constraints by combining them as one hybrid strategy. A modification of PID controller constraints is needed for more precise control mechanism. The PID controller is restricted because of the constant constraints $K p, K i$, and $K d$. This makes the output of the control system not adaptable. Instead, a smart adaptive control is proposed, which can adapt the control constraints to increase the accuracy of the system. Having the ability of learning and adaptableness of neural network, the controller can resolve the aforementioned problems. The PID controller constraints will be adjusted and adapted using the neural network so as to decrease the position error regarding external disruptions.

The primary motivation behind this research is to bridge the gap that exists in academia related to hybrid fixed-wing aircraft control techniques. Many research articles can be found on the fixed-wing tilt-rotor gyroplanes using PID control or adaptive control. This paper instead presents a novel hybrid control technique that combines both the PID and the neural network adaptive controller.

The main contributions of this research are to construct a new and novel model of aircraft that has the abilities of both the (VTOL) and fixed-wing aircraft, to mathematically model the aerodynamics of the aircraft, and to develop a novel, hybrid control strategy using both the PID control and the neural network adaptive control.

The remainder of the paper is as follows. Section 2 presents cutting-edge research in fixed-wing aircraft. Then, Section 3 presents the dynamics of the fixed-wing aircraft including the analysis of inflow velocity, blade force analysis, and factors influencing the blade speed. Afterward, Section 4 offers the mathematical modeling of the rotor, wings, and vertical and horizontal tails. Then, Section 5 analyzes attitude, speed, altitude, turn, and take-off control and designs a hybrid control mechanism. Section 6 presents the simulation platform and its results. Lastly, Section 7 concludes the whole research.

\section{State of the Art}

This section presents some of the cutting-edge research into fixed-wing aircraft and their control design. Reference [16] modifies the classic model reference adaptive controller to apply it to the station-keeping and landing of a fixed-wing aircraft on a moving platform. It achieves translational maneuvers without a change in pitch and roll attitude. It does so by fitting the aircraft with side force control and utilizing the direct lift control flaps. The paper proposes a reference model such that position and heading can be matched synchronously at touchdown. Their approach differs from the previous works as many researchers did not explicitly address the attitude match problem. Lastly, the results verify the efficiency of the suggested algorithm. In another recent research on fixedwing aircraft, reference [17] offers a new design of the aerial vehicle with independently tilt wings for different flight movements. Contrary to traditional tilt wing aircraft, this study attains the thrust vectoring and direction control of the aircraft by tilting the main wings separately. These independently tilted wings help achieve more effective movements of the aerial vehicle. A fixedwing aircraft with individually tilted main wings is a rather new phenomenon in the aviation industry. It uses the PID and PI controller for flight movement control. The results of simulations and experiments prove the better efficiency of the proposed model than traditional aircraft. 


\section{Dynamics of the Fixed-Wing UAV}

An aircraft is able to spin around three axes from the center of gravity of the plane. The position control of the gyrocopter is typically transformed into the angular control, namely, roll, pitch, and yaw $(\varphi, \theta, \psi)[18]$. Figure 2 presents the aircraft with the reference coordinate systems. To describe the movements of the gyroplane, two reference systems are required: the earth frame and the body frame. The movement of the aircraft is calculated by geographical maps; that is why this study uses an Earth frame. The starting point of this system attaches to the surface of the Earth, and the axes $\left(X_{e}, Y_{e}\right.$, and $\left.Z_{e}\right)$ are pointed to corresponding coordinates. The body frame system $\left(X_{b}, Y_{b}\right.$, and $Z_{b}$ ) is the fixed body system that is positioned in the gravity center of the gyrocopter where $\gamma_{1}$ and $\gamma_{2}$ represent the tilt angles of the servo motors. Figure 3 shows the model of the proposed aircraft with two propellers and a rotor.

The key control inputs for a fixed-wing air vehicle are as follows:

(a) Throttle: it controls the engine speed and, therefore, the movement of the propeller [19]. Throttle handles not only the forward speed of the aircraft but also, more importantly, the rate of rising and fall, since various airspeeds generate various extents of lift [20]. You can lift the aircraft a little without affecting the speed just by increasing throttle. On the other hand, reducing the throttle will make the airplane descend before the speed decreases.

(b) Blade pitch: the hinged part of the horizontal tail controls the pitch of the aircraft as shown in Figure 3. They are at the back of the aircraft and are some of the most significant control inputs. Blade pitch controls the pitch attitude of the aircraft, i.e., whether the aircraft's nose moves up or down [21]. The nose of the aircraft points up when the blade pitch is up and it points down when the blade pitch is down.

(c) Thrust vectors: thrust vectors manage the turning of the aircraft [22]. They function as opposed to each other which means that when one of them goes upwards, the other one goes downwards. Thrust vectors function by varying the lift over the wing. As a thrust vector goes up, it disturbs the flow of air over that wing and so the lift is decreased a little. The thrust vector on the other wing goes down and the lift increases a bit. Consequently, the aircraft tilts and, therefore, turns to the side that's undergoing decreased lift.

3.1. Inflow Velocity of the Rotor. The inflow velocity $V$ is divided into two main components as shown in Figure 4(a) and given as follows:

$$
V \stackrel{\text { breaks down into }}{\longrightarrow}\left\{\begin{array}{l}
V \cos \alpha_{R}, \\
V \sin \alpha_{R} .
\end{array}\right.
$$

Taking a blade at a radius $r$ as an example, the tangential inflow velocity $u_{t}$ and perpendicular inflow velocity $u_{p}$ of the blade can be obtained by combining the rotor speed $\Omega$ and the blade angle $\psi_{s}$ as shown in Figure $4(\mathrm{~b})$ and given as follows:

$$
\left\{\begin{array}{l}
u_{t}=V \cos \alpha_{R} \sin \psi_{s}+\Omega r \\
u_{p}=V \sin \alpha_{R}+v+v_{\beta},
\end{array}\right.
$$

where $v$ represents the speed of rotating blades and $v_{\beta}$ is the induced speed of the blade.

3.2. Blade Force Analysis. The aerodynamic force acting on the profile is arbitrarily intercepted at a certain radius of the blade as shown in Figure 5.

According to Figure 5, it is concluded that

$$
\begin{aligned}
& \left\{\begin{array}{l}
\mathrm{d} L=c_{L} \frac{1}{2} \rho u^{2} c \mathrm{~d} r, \\
\mathrm{~d} D=c_{D} \frac{1}{2} \rho u^{2} c \mathrm{~d} r,
\end{array}\right. \\
& \left\{\begin{array}{l}
\mathrm{d} F_{p}=\mathrm{d} L \cdot \cos \varepsilon+\mathrm{d} D \cdot \sin \varepsilon, \\
\mathrm{d} F_{t}=\mathrm{d} L \cdot \sin \varepsilon-\mathrm{d} D \cdot \cos \varepsilon,
\end{array}\right. \\
& \mathcal{E}=\arctan \frac{u_{p}}{u_{t}} .
\end{aligned}
$$

Now, to get the center torque of the hub,

$$
\mathrm{d} Q=\mathrm{d} F_{t} \cdot r=\frac{1}{2} \rho u^{2}\left(c_{L} \sin \varepsilon-c_{D} \cos \varepsilon\right) c r \mathrm{~d} r .
$$

In equations (3)-(6), blade force analysis parameters have been presented in order to understand the dynamics of the proposed system. It can be seen that the torque acting on the blade varies as per the equation that can produce initial torque and maintain the constant speed while in motion.

Furthermore, the rotor speed of the blade is given by

$$
\Omega=\frac{1}{I_{b}} \int Q_{R} \mathrm{~d} t,
$$

where the moment of inertia is $I_{b}$. Now, to define the angle $\varepsilon^{\prime}$,

$$
\varepsilon^{\prime}=\arctan \frac{\mathrm{d} D}{\mathrm{~d} L}=\arctan \frac{C_{L}}{C_{D}}=\arctan \frac{1}{k_{c}},
$$

where $k_{c}$ is the ratio of blade radius to drag.

When the component $\mathrm{d} F$ of the aerodynamic resultant force $\mathrm{d} R$ in the rotating plane is consistent with the rotation direction, it drives the blade. When the direction is opposite to the rotation direction, it hinders the blade.

When $\varepsilon^{\prime}<\varepsilon$, the blades in the radius section rotate in the same direction, which drives the blades. Conversely, when $\varepsilon^{\prime}>\varepsilon$, it hinders the blades.

When the hindering condition $\varepsilon^{\prime}>\varepsilon$, it establishes

$$
\arctan \frac{1}{k_{c}}<\arctan \frac{u_{p}}{u_{t}} \text {. }
$$

Substituting the values of $u_{p}$ and $u_{t}$ results in 


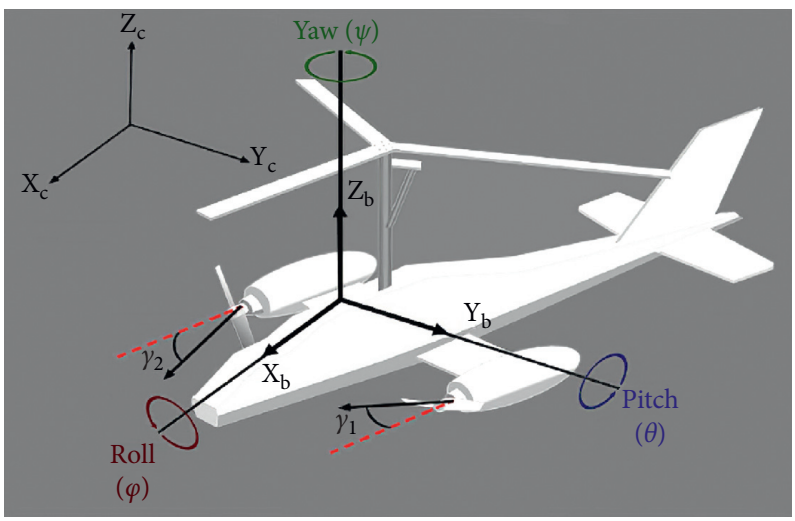

Figure 2: Reference frame systems.

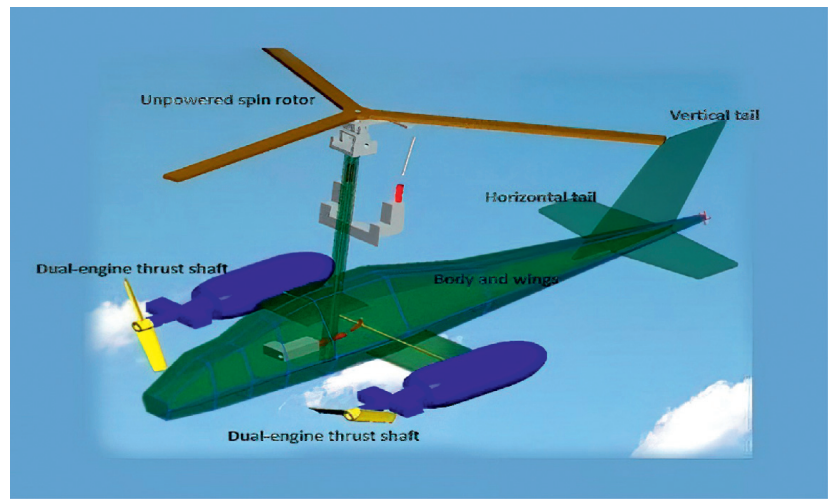

FIGURE 3: Our designed aircraft model.

$$
r>\frac{k_{c}\left(V \sin \alpha_{R}+v+v_{\beta}\right)-V \cos \alpha_{R} \sin \psi_{s}}{\Omega} .
$$

For the different sections of blade radius $r$, the stop and drive sections on the blade will change periodically with the blade angle $\psi_{s}$. However, the rotor speed will remain constant.

When $\psi_{s} \in\left[0^{\circ}, 180^{\circ}\right]$, the part near the tip of the propeller is the stopping section, which is relatively long. When $\psi_{s} \in\left[0^{\circ}, 180^{\circ}\right]$, $\sin \psi_{s}<0$ and the stopping section is relatively short. When $\psi_{s}=90^{\circ}$ or $270^{\circ}$, the stopping section is the longest.

3.3. Factors Affecting Rotor Speed. Figure 6 explains the effects of inflow velocity and the rotor's angle of attack on rotor speed.

As is apparent from Figure 6, the rotation speed of the rotor increases with the increase of inflow velocity and the angle of attack of the rotor. Figure 7 presents the rotor speed curve which is obtained from the ground blowing test.

Keeping the propeller angle of attack fixed at $4^{\circ}, 6^{\circ}$, and $8^{\circ}$, the curve of the increasing speed of the rotor is obtained when the inflow velocity changes as shown in Figure 7.

When the propeller angle of attack is constant, the rotor speed increases with the increase in inflow velocity. When the inflow velocity is constant, the rotor speed rises with the increase in the propeller angle of attack.
3.4. Stability Analysis. When the center of gravity is above the vector thrust axis, it is called the high center of gravity state. When the center of gravity is below the vector thrust axis, it is called a low center of gravity state. No matter the state of the center of gravity, the aircraft will be in a balanced state only when the total torque of the body is zero. In the stability analysis of the aircraft body, the relationship between torque produced by thrust vectors $M_{T}$ and torque generated by rotor pull force $M_{J}$ is as follows:

$$
M_{T}+M_{J}=0
$$

As shown in Figure 8, the aircraft has a low center of gravity state. In this state, suppose that a gust of wind interference is given to the airframe, causing the airframe and the main rotor blade to produce a positive pitch. Therefore, the rotor increases the angle of attack $\Delta \alpha$, and the main rotor pull force changes from $F_{J 1}$ to $F_{J 2}$. The angle will further increase the rotor speed. As the pulling force generated by the main rotor and the relative center arm increases, so an additional head-up torque $\Delta M_{y}$ will be generated, which further increases the airframe and main rotor angle of attack. In the same way, when the airframe is initially given a gust of interference to cause the airframe and the main rotor blade to pitch in a negative direction, the angle of attack of the airframe and 


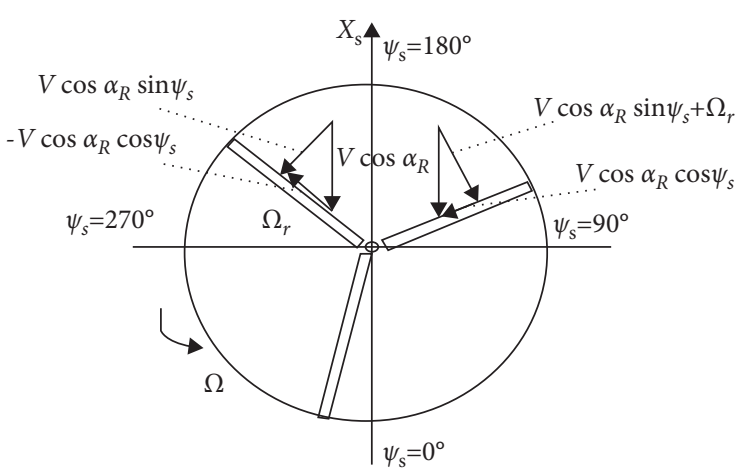

(a)

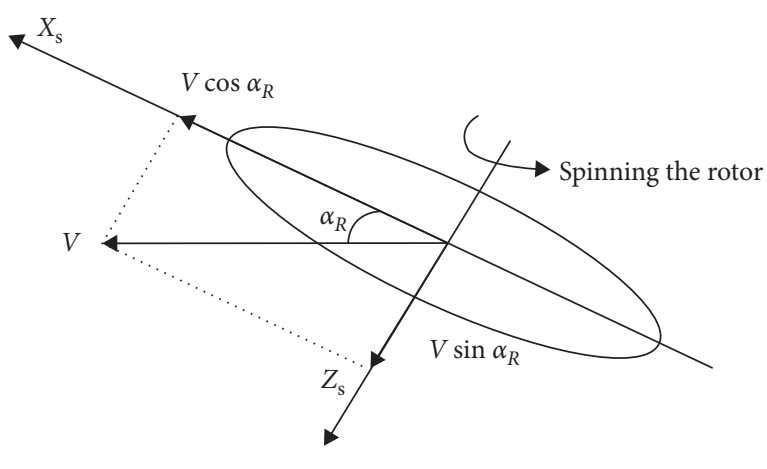

(b)

FIGURE 4: Inflow velocity analysis. (a) Breakdown of inflow velocity. (b) Tangential and perpendicular inflow velocity.

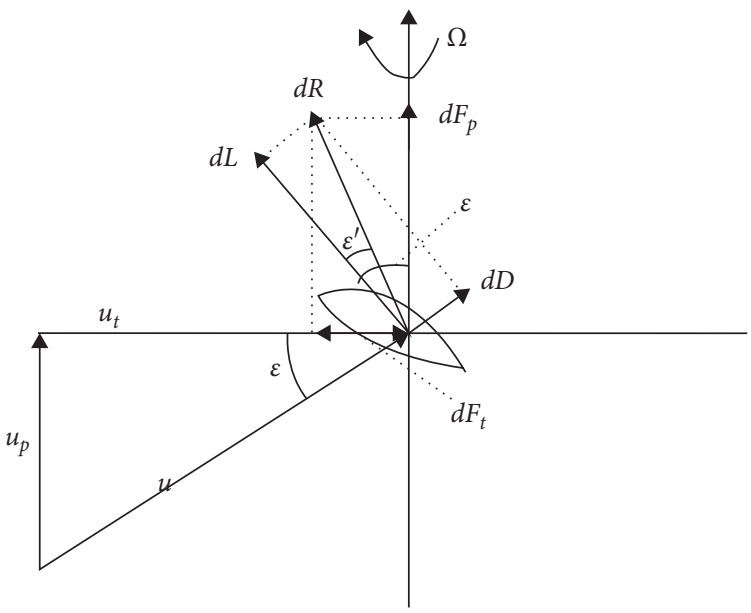

Figure 5: Blade force analysis.

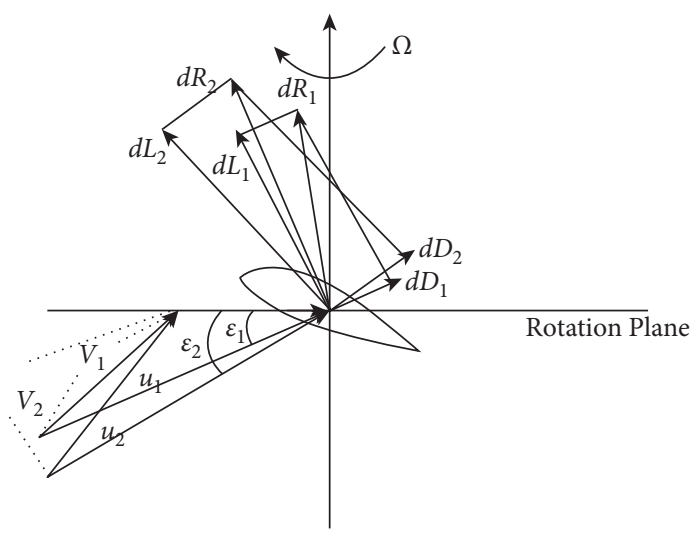

FIGURE 6: Factors affecting rotor speed. 


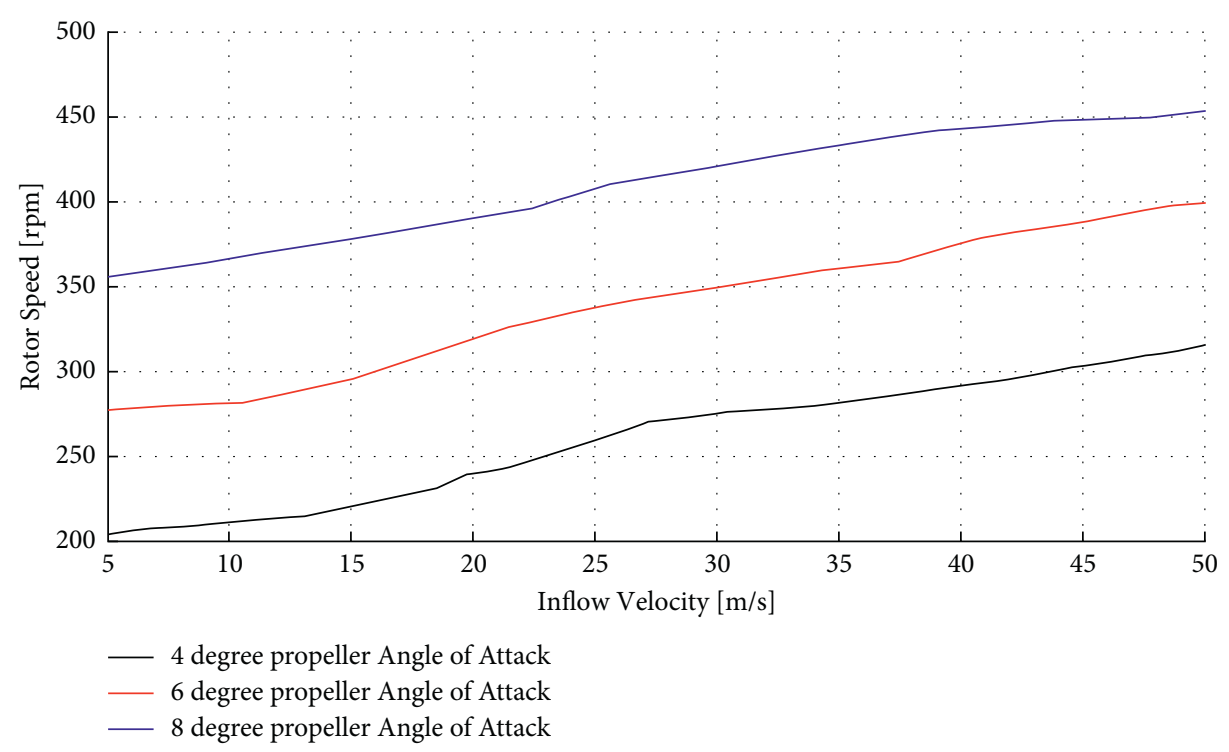

Figure 7: The relationship between rotor speed and inflow velocity.

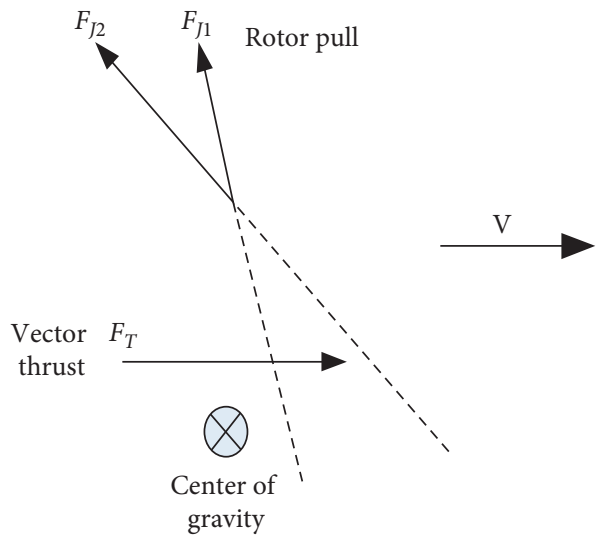

FIGURE 8: Stability of the aircraft body at a low center of gravity.

the main rotor will be further reduced under the action of the main rotor blade. Therefore, the aircraft in the low center of gravity configuration is unstable, which can be represented mathematically as

$$
\frac{\Delta M_{y}}{\Delta \alpha}>0
$$

As shown in Figure 9, the aircraft has a high center of gravity state. At this time, a gust of wind interference is also given to the body. The angle of attack of the rotor blade increases $\Delta \alpha$, and the main rotor pull force changes from $F_{J 1}$ to $F_{J 2}$. At this time, the increased angle of attack will further increase the rotor speed. Although the force arm decreases, the increase in the pulling force of the rotor is more obvious, so an additional head-down torque is formed, which reduces the angle of attack of the body. Therefore, the aircraft under the high center of gravity configuration is stable, which can be represented mathematically as

$$
\frac{\Delta M_{y}}{\Delta \alpha}<0 .
$$

\section{Mathematical Modeling}

This section presents the mathematical modeling of the proposed aircraft. First, the modeling of the rotor is discussed when it is idle. Secondly, the wings and horizontal and vertical tails of the fixed-wing aircraft are modeled. Finally, the full-state modeling of the complete gyroplane is explained. When the rotor rotates at a high speed around the axis and tilts because of 
the steering gear, the motor generates a gyro moment of the impedance rotating shaft. The gyro moment can somewhat affect the control performance and has been discussed extensively in previous research articles.

4.1. Modeling of the Idle Rotor. When the rotor spins, the component forces in three directions of $r$ radius are $\mathrm{d} F_{p}$, $\mathrm{d} F_{t}$, and $\mathrm{d} F_{r}$ where equation (11) represents mathematically the following:

$$
\left\{\begin{array}{l}
\mathrm{d} F_{p}=\frac{1}{2} \rho u^{2}\left(c_{L} \cos \varepsilon+c_{D} \sin \varepsilon\right) \cdot c \mathrm{~d} r, \\
\mathrm{~d} F_{t}=\frac{1}{2} \rho u^{2}\left(c_{L} \sin \varepsilon-c_{D} \cos \varepsilon\right) \cdot c \mathrm{~d} r, \\
\mathrm{~d} F_{r}=\frac{1}{2} \rho u^{2}\left(c_{L} \cos \varepsilon+c_{D} \sin \varepsilon\right) \cdot \sin \beta \cdot c \mathrm{~d} r,
\end{array}\right.
$$

where $\beta$ is the spinning angle of the rotor. Equation (12) presents the force and moment of the propeller disc.

$$
\left\{\begin{array}{l}
T_{R}=k \int_{0}^{2 \pi} \int_{0}^{R} \mathrm{~d} F_{p}\left(\psi_{s}\right), \\
S_{R}=k \int_{0}^{2 \pi} \int_{0}^{R} \mathrm{~d} F_{t}\left(\psi_{s}\right) \cos \psi_{s}-\mathrm{d} F_{r}\left(\psi_{s}\right) \sin \psi_{s}, \\
K_{R}=k \int_{0}^{2 \pi} \int_{0}^{R} \mathrm{~d} F_{p}\left(\psi_{s}\right) \sin \psi_{s}-\mathrm{d} F_{r}\left(\psi_{s}\right) \cos \psi_{s}, \\
M=k \int_{0}^{2 \pi} \int_{0}^{R}-r \mathrm{~d} F_{p}\left(\psi_{s}\right) \sin \psi_{s}, \\
Q=k \int_{0}^{2 \pi} \int_{0}^{R} r \mathrm{~d} F_{t}\left(\psi_{s}\right),
\end{array}\right.
$$

where $k$ and $R$ represent the number of blades and the radius of the rotor blades, respectively.

4.2. Modeling of Dual-Engine Variable Thrust Axis. Figure 10 presents the schematic illustration of the singleengine variable thrust axis, where $\left(x_{p}, y_{p}, z_{p}\right)$ is the position of the engine thrust point and $\alpha_{p}$ is the thrust axis angle. The force and moment of the left and right engines on the aircraft can be obtained as

$$
\left\{\begin{array}{l}
{\left[\begin{array}{c}
F_{x} \\
F_{y} \\
F_{z}
\end{array}\right]_{p r}=\left[\begin{array}{c}
T_{p r} \cos \alpha_{p r} \\
0 \\
T_{p r} \sin \alpha_{p r}
\end{array}\right],} \\
{\left[\begin{array}{c}
F_{x} \\
F_{y} \\
F_{z}
\end{array}\right]_{p l}=\left[\begin{array}{c}
T_{p l} \cos \alpha_{p l} \\
0 \\
T_{p l} \sin \alpha_{p l}
\end{array}\right]}
\end{array}\right.
$$

$$
\left\{\begin{array}{l}
{\left[\begin{array}{l}
M_{x} \\
M_{y} \\
M_{z}
\end{array}\right]_{p r}=\left[\begin{array}{c}
Q_{p r} \cos \alpha_{p r} \\
0 \\
Q_{p r} \sin \alpha_{p r}
\end{array}\right]+\left[\begin{array}{ccc}
0 & -z_{p} & y_{p} \\
z_{p} & 0 & -x_{p} \\
-y_{p} & x_{p} & 0
\end{array}\right]\left[\begin{array}{l}
F_{x} \\
F_{y} \\
F_{z}
\end{array}\right]_{p r},} \\
{\left[\begin{array}{l}
M_{x} \\
M_{y} \\
M_{z}
\end{array}\right]_{p l}=\left[\begin{array}{c}
Q_{p l} \cos \alpha_{p l} \\
0 \\
Q_{p l} \sin \alpha_{p l}
\end{array}\right]+\left[\begin{array}{ccc}
0 & z_{p} & y_{p} \\
-z_{p} & 0 & -x_{p} \\
-y_{p} & x_{p} & 0
\end{array}\right]\left[\begin{array}{l}
F_{x} \\
F_{y} \\
F_{z}
\end{array}\right]_{p l},}
\end{array}\right.
$$

$$
\left\{\begin{array}{l}
{\left[\begin{array}{l}
F_{x} \\
F_{y} \\
F_{z}
\end{array}\right]_{p}=\left[\begin{array}{l}
F_{x} \\
F_{y} \\
F_{z}
\end{array}\right]_{p r}+\left[\begin{array}{l}
F_{x} \\
F_{y} \\
F_{z}
\end{array}\right]_{p l},} \\
{\left[\begin{array}{l}
M_{x} \\
M_{y} \\
M_{z}
\end{array}\right]_{p}=\left[\begin{array}{l}
M_{x} \\
M_{y} \\
M_{z}
\end{array}\right]_{p r}+\left[\begin{array}{l}
M_{x} \\
M_{y} \\
M_{z}
\end{array}\right]_{p l} .}
\end{array}\right.
$$

4.3. Modeling of the Wings and Horizontal and Vertical Tails. Consider the fuselage and wings together to model their aerodynamic force and moment which can be given as

$$
\left\{\begin{array}{l}
{\left[\begin{array}{c}
F_{x} \\
F_{y} \\
F_{z}
\end{array}\right]_{p}=\left[\begin{array}{l}
C_{X b} \\
C_{Y b} \\
C_{Z b}
\end{array}\right] Q_{b} S_{b}} \\
{\left[\begin{array}{c}
M_{x} \\
M_{y} \\
M_{z}
\end{array}\right]_{p}=\left[\begin{array}{l}
C_{L b} \\
C_{M b} \\
C_{N b}
\end{array}\right] Q_{b} S_{b} l_{b} .}
\end{array}\right.
$$

The aerodynamic force and moment of horizontal tail is

$$
\left\{\begin{array}{l}
{\left[\begin{array}{l}
F_{x} \\
F_{y} \\
F_{z}
\end{array}\right]_{h s}=T_{h s}\left[\begin{array}{c}
-C_{D h s} \\
0 \\
-C_{L h s}
\end{array}\right] Q_{h s} S_{h s},} \\
{\left[\begin{array}{l}
M_{x} \\
M_{y} \\
M_{z}
\end{array}\right]_{h s}=\left[\begin{array}{ccc}
0 & z_{h s} & -y_{h s} \\
-z_{h s} & 0 & x_{h s} \\
y_{h s} & -x_{h s} & 0
\end{array}\right]\left[\begin{array}{l}
F_{x} \\
F_{y} \\
F_{z}
\end{array}\right]_{h s} .}
\end{array}\right.
$$

The aerodynamic force and moment of vertical tail is 


$$
\left\{\begin{array}{l}
{\left[\begin{array}{c}
F_{x} \\
F_{y} \\
F_{z}
\end{array}\right]_{v t}=T_{v t}\left[\begin{array}{c}
-C_{D v t} \\
C_{Y v t} \\
0
\end{array}\right] Q_{v t} S_{v t},} \\
{\left[\begin{array}{l}
M_{x} \\
M_{y} \\
M_{z}
\end{array}\right]_{v t}=\left[\begin{array}{ccc}
0 & z_{h s} & -y_{h s} \\
-z_{h s} & 0 & x_{h s} \\
y_{h s} & -x_{h s} & 0
\end{array}\right]\left[\begin{array}{l}
F_{x} \\
F_{y} \\
F_{z}
\end{array}\right]_{v t} .}
\end{array}\right.
$$

4.4. Full-State Modeling of the Aircraft. Figure 11 presents the full-state model of the proposed aircraft. By using aerodynamics and particle mechanics, the models of the idle rotor, twin-engine variable thrust axis, fuselage, wings, and horizontal tail and vertical tail, are established, respectively. The resultant force and moment are unified and transformed into the body coordinate system.

Equation (19) presents the resultant aerodynamic force and moment of the aircraft mathematically.

$$
\left\{\begin{array}{l}
F_{\Sigma}=\left[\begin{array}{c}
F_{x} \\
F_{y} \\
F_{z}
\end{array}\right]_{\text {resultant }}=\left[\begin{array}{c}
F_{x} \\
F_{y} \\
F_{z}
\end{array}\right]_{\text {Rotor }}+\left[\begin{array}{c}
F_{x} \\
F_{y} \\
F_{z}
\end{array}\right]_{\text {Thrust }}+\left[\begin{array}{c}
F_{x} \\
F_{y} \\
F_{z}
\end{array}\right]_{\text {Fuselage }}+\left[\begin{array}{c}
F_{x} \\
F_{y} \\
F_{z}
\end{array}\right]_{\text {Horizontal tail }}+\left[\begin{array}{c}
F_{x} \\
F_{y} \\
F_{z}
\end{array}\right]_{\text {Vertical tail }}, \\
\left.M_{\Sigma}=\left[\begin{array}{l}
M_{x} \\
M_{y} \\
M_{z}
\end{array}\right]_{\text {resultant }}=\left[\begin{array}{c}
M_{x} \\
M_{y} \\
M_{z}
\end{array}\right]_{\text {Rotor }}+\left[\begin{array}{c}
M_{x} \\
M_{y} \\
M_{z}
\end{array}\right]_{\text {Thrust }}^{M_{x}}+\left[\begin{array}{c}
M_{x} \\
M_{y} \\
M_{z}
\end{array}\right]_{\text {Fuselage }}+\left[\begin{array}{c}
M_{y} \\
M_{z}
\end{array}\right]_{\text {Horizontal tail }} M_{z}\right]_{\text {Vertical tail }}
\end{array}\right.
$$

\section{Designing of Flight Control Strategy}

In this section, the attitude, speed, altitude, turn, and take-off control are discussed. At the end of this section, the hybrid control mechanism is also discussed in detail.

5.1. Attitude Control. The rotor blade provides the main lift and control surface. Dual-engine variable axis thrust is the main control mechanism, which constitutes control of the rotorcraft. Attitude control of the rotor blade represented by $\delta_{e}$ can be given as

$$
\delta_{e}=K_{\theta e}\left(\theta_{d}-\theta\right)+\int K_{i \theta e}\left(\theta_{d}-\theta\right) d t+K_{q e} q .
$$

Attitude control of the dual-engine variable thrust axis is

$$
\left\{\begin{array}{l}
\Delta \delta_{a \phi}=K_{\phi}\left(\phi_{d}-\phi\right)+\int K_{i \phi}\left(\phi_{d}-\phi\right) \mathrm{d} t+K_{p} p, \\
\Delta \delta_{a \theta}=K_{\theta a}\left(\phi_{d}-\phi\right)+\int K_{i \phi a}\left(\phi_{d}-\phi\right) \mathrm{d} t+K_{q a} q, \\
\delta_{a l}=-\Delta \delta_{a \phi}+\Delta \delta_{a \theta}, \\
\delta_{a r}=\Delta \delta_{a \phi}+\Delta \delta_{a \theta} .
\end{array}\right.
$$

Figure 12 presents the dissection of the lateral force acting on the rotor aircraft when it turns. To balance this force, the conditions are

$$
\left\{\begin{array}{c}
\left(T_{R} \cos \theta_{R}+T_{p} \sin \alpha_{p l}-T_{p} \sin \alpha_{p r}\right) \cos \phi+L=G \\
\left(T_{R} \cos \theta_{R}+T_{p} \sin \alpha_{p l}-T_{p} \sin \alpha_{p r}\right) \sin \phi=\frac{m V^{2}}{R} \\
T_{R} \sin \theta_{R}+D-T_{p} \cos \alpha_{p l}-T_{p} \cos \alpha_{p r}=0 \\
\Delta \phi_{d}=K_{d} d+\int\left(K_{i d} d\right) \mathrm{d} t+K_{\dot{d}} \dot{d}
\end{array}\right.
$$

5.2. Speed Control. The main factors affecting the speed of the rotor aircraft are the resistance of the rotor blade and the forward thrust of the engine. The closed-loop control of the speed is implemented by manipulating the relative pitch angle of the rotor blade and the engine thrust. The best control effect cannot be achieved by operating alone. Therefore, considering the influence of blade resistance, it is essential to coordinate and change the pitch angle of the rotor when controlling the speed. The pitch angle of the rotor blade is given as

$$
\Delta \theta_{d}=K_{\theta V}\left[K_{V}\left(V_{d}-V\right)+K_{i V} \int\left(V_{d}-V\right) \mathrm{d} t\right] .
$$




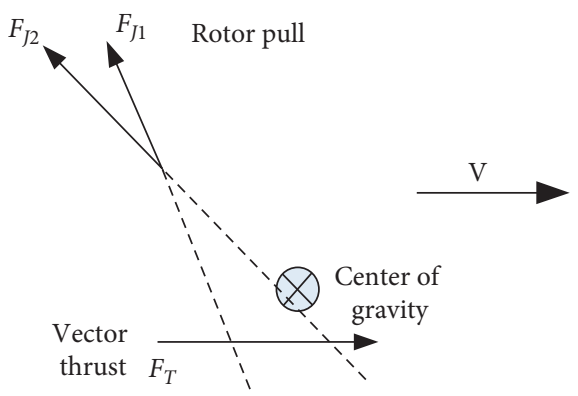

FIGURE 9: Stability of the aircraft body under a high center of gravity.

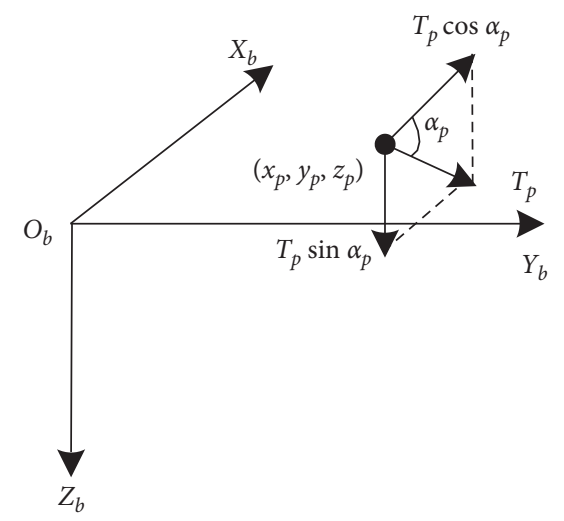

FIgURE 10: Single-engine variable thrust axis.

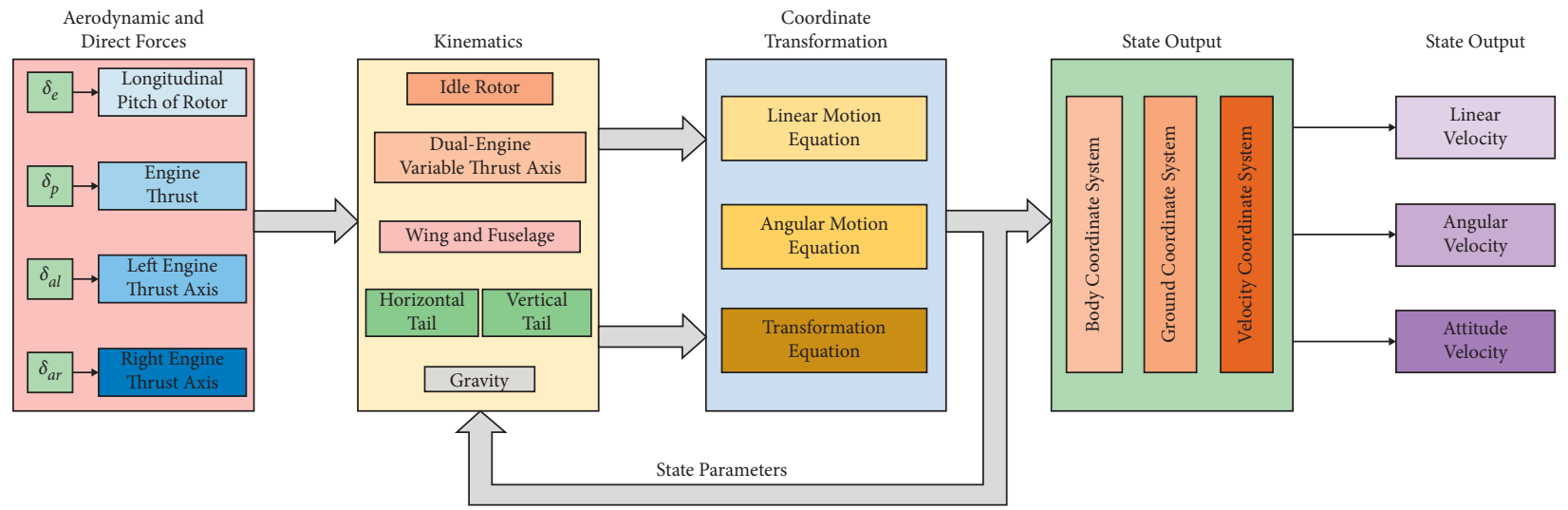

FIgURE 11: The full-state model of the proposed aircraft.

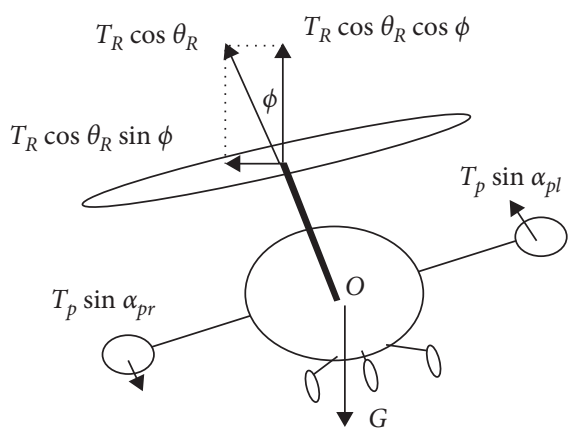

Figure 12: The lateral force of rotorcraft turning. 
5.3. Altitude Control. Due to the rotation characteristics of the unmanned rotor aircraft, the pull force of the rotor blade is related to the angle of attack and the inflow velocity, so increasing the angle of attack or the speed of the rotor aircraft can increase the lift of the rotor aircraft and increase the altitude.

Coordinated manipulation of the thrust axis of the engine can directly change the amount of lift, but it will reduce the speed which is given as

$$
\Delta n_{d}=K_{n H}\left[K_{H}\left(H_{d}-H\right)+\int K_{i H}\left(H_{d}-H\right) d t+K_{\dot{H}} \dot{H}\right] .
$$

Figure 13 shows the aircraft when it takes off and breaks down the various forces and moments acting upon it which are given as

$$
\left\{\begin{array}{l}
\theta \in\left[0, \theta_{b}\right], \theta_{b}=\arctan \left[\frac{\left(h_{f}-\Delta h_{f}\right)-\left(h_{r}-\Delta h_{r}\right)}{l_{f}+l_{r}}\right] \\
\phi \in[-\phi(h), \phi(h)], \phi(h)=\arcsin \frac{h}{h_{\max }}-\arcsin \frac{h_{\min }}{h_{\max }}, h \in\left[h_{\min }, h_{\max }\right] .
\end{array}\right.
$$

The equation of longitudinal motion is

$$
\left\{\begin{array}{l}
m \frac{\mathrm{d} V}{\mathrm{~d} t}=T_{p}\left(\cos \alpha_{p l}+\cos \alpha_{p r}\right) \cos \alpha-T_{R} \sin \alpha_{R}-G \sin \gamma-D-F_{f}-F_{m} \\
m \frac{\mathrm{d} \alpha}{\mathrm{d} t}=m V q-T_{p}\left(\sin \alpha_{p l}+\sin \alpha_{p r}\right) \sin \alpha-T_{R} \cos \alpha_{R}-L+G \cos \gamma-\left(N_{f}+N_{m}\right) \cos \alpha+\left(F_{f}+F_{m}\right) \sin \alpha \\
M_{y}=I_{z} \dot{q} \\
\gamma=\theta-\alpha
\end{array}\right.
$$

5.4. Hybrid Control Mechanism. Developing a control mechanism for the aircraft is the most essential feature of this study. Several control strategies for our project including using only PID and LQR or using neural networks have been analyzed. After examining different algorithms, we concluded that the best mechanism for our aircraft would be a hybrid of PID and neural networks. These algorithms and their combination are disused hereinafter.

5.4.1. PID Control. Control systems are generally divided into two categories, open- and closed-loop systems [23, 24]. Proportional-Integral-Derivative (PID) controller allows us to enable feedback and use control action, and as a result, a close-loop control system is attained. In PID controller, a feedback signal is used which senses the plant output and transmits it back so that the system is able to adjust appropriately. In feedback control, there is a reference signal which is the preferred setting. Then, the system compares the reference signal with the feedback signal. The difference between the reference and the feedback signal is the error. The error is then sent to a controller which turns it into an instruction that is then again directed to the plant. The PID controller forces the error to become zero as with more iterations.

5.4.2. Hybrid Control Using Neural Networks. Neural networks are powerful tools that are capable of approximating numerous linear and nonlinear functions. In many cases, these networks can adjust to varying input-output relations. These NN can also correctly map multivariable functions. They are simple to implement in hardware as well.

A modification of PID controller constraints is needed for a more precise control mechanism. The PID controller is restricted because the constraints $K_{p}, K_{i}$, and $K_{d}$ are constants. This makes the output of the control system not adaptable. Instead, smart adaptive control is proposed, which can adapt the control constraints to increase the accuracy of the system. Having the ability of learning and adaptability of neural networks, the controller can resolve the aforementioned problems. The PID controller constraints will be adjusted and adapted in the best way so as to decrease the position error regarding 


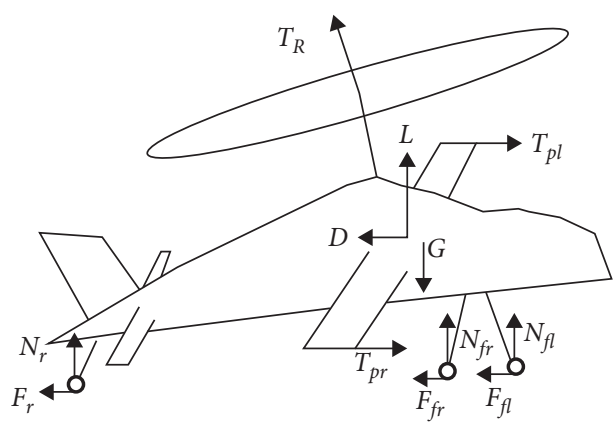

Figure 13: Take-off diagram.

external disruptions. External disruption could include a dynamic environment or rough weather which could knock the aircraft off the track.

Figure 14 represents the block diagram of the neural network. The parameters used are $K_{p}$ which is the PID proportional gain, $K_{d}$ is the derivative gain, and $K_{i}$ is the PID integral gain whereas $e_{p}$ is the system error between desired and actual output, $e_{i}$ is integral of the system error, and $e_{d}$ is the difference of the system error. On the other hand, $x(k)$ is the input signal of the sigmoid function and $\operatorname{sat}_{M}(x)$ is a nonlinear saturated sigmoid function. Finally, $k$ is the discrete step sequence.

Figure 15 presents the structure of the nonlinear PID controller using a neural network for a single Degree of Freedom (DOF). In this example, consider that the pitch angle but the control algorithm will be implemented in the same way for other degrees of freedom (altitude, yaw, and roll) as well. Neural networks are trained by the traditional backpropagation algorithm to reduce the system error between the desired and actual output. In this figure, $\theta_{d}(k)$ and $\theta(k)$ represent the desired and actual pitch angle, respectively, while $\Delta T$ is the sampling time and $M_{\theta}(k)$ denotes the torque generated by the pitch of the aircraft body.

Figure 16 presents the block diagram of the hybrid controller. In this figure, $r(t)$ represents the desired value, $u(t)$ is the control variable, $y(t)$ is the process variable, $y_{r}(t)$ is the referenceadjusted process variable, and $e(t)$ is the error value.

\section{Simulation and Discussions}

6.1. Testing Platform. Table 1 presents the technical specifications of the fixed-wing aircraft. The aircraft weighs almost $300 \mathrm{~kg}$ even without payload. It has a maximum speed of around $250 \mathrm{~km} / \mathrm{h}$ and needs 15 -meter runway to take off.

Figure 17 presents the overall framework of the system. As is apparent in the figure, the two main parts of the system are a ground part and an airborne part. The ground part mainly consists of the ground control station, antenna, and display computer. The airborne part has a radio, antenna, sensors, and a central processing unit that controls the whole process.

Figure 18 shows the ground measurement and control station. The ground measurement and control station mainly includes a human-machine interface, serial
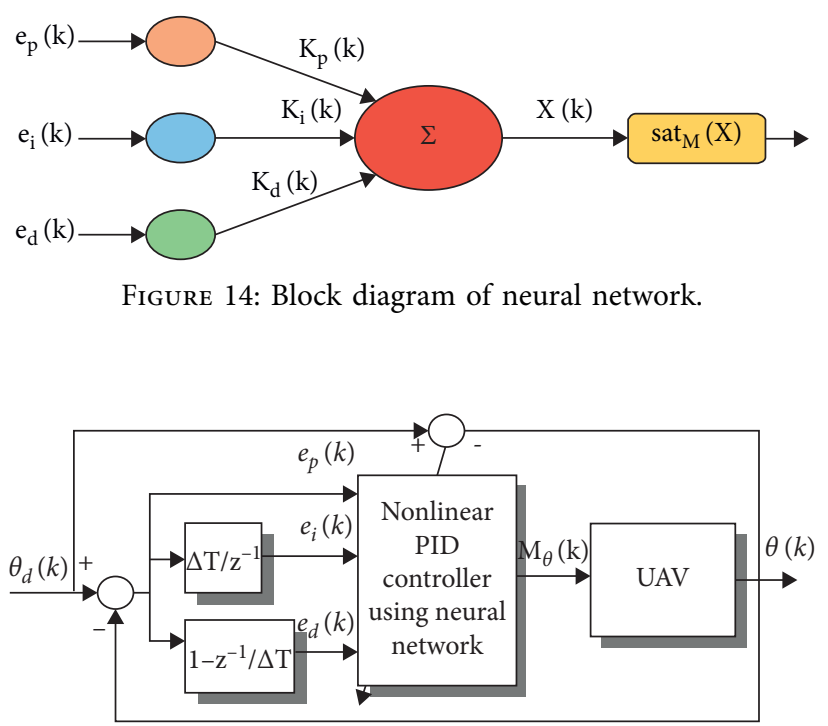

FIgURE 15: Structure of the nonlinear PID controller using neural network.

communication, and data storage modules. The software of ground measurement and control station is developed with $\mathrm{C}++$ language under the $\mathrm{VC}$ development platform, and the dynamic control, GMS control, and NI active control are used for programming. Serial communication is to send remote control data at fixed time intervals and interrupt to receive telemetry data sent by the flight control computer. The human-machine interface (HMI) contains the following main modules: GPS parameter information, rotorcraft flight status information, steering gear output information, joystick lever, button information, flight mode display information, simulated attitude change animation, and signal light display. The operator can conveniently control the rotorcraft flight in real time through the HMI. Figure 19 presents the prototype of the fixed-wing aircraft which contains the airborne part of the overall control system.

6.2. Simulation Test. The simulation test of the proposed aircraft is essential to prove the relevant control strategy and flight control system designs are able to control the maneuvering of the aircraft. On the basis of the whole aircraft flight control system, a simulation computer is added to form a semiphysical simulation platform. Figure 20 presents the simulation platform.

The core of the aircraft simulation model is the mathematical model written in $\mathrm{C}++$ language. The numerical integration method is used to express the 12th-order differential equation of the model, and the fourth-order Runge-Kutta method is selected. Considering the working resources of the computer and the need for simulation accuracy, the integration step is set at 5 milliseconds. The working principle of simulation is as follows; when the communication of the whole simulation system is connected, the take-off instructions are sent by the ground measurement and control station, and the flight control 


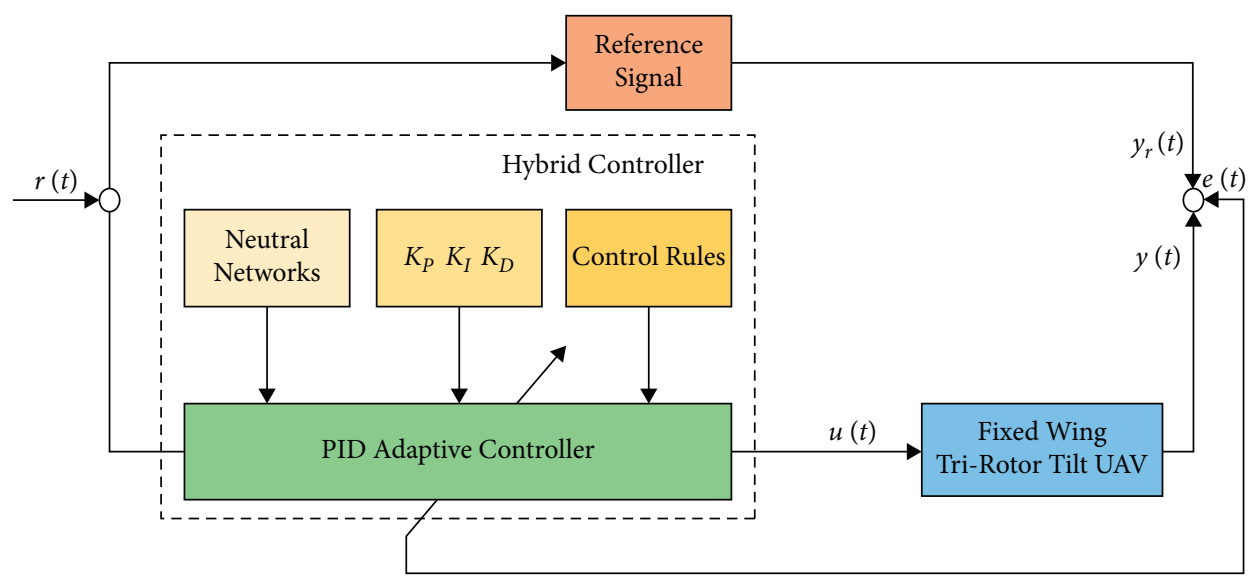

FIGURE 16: Block diagram of the proposed hybrid controller.

TABle 1: Technical specifications of the aircraft.

\begin{tabular}{lc}
\hline Parameter & Value \\
\hline Total weight (without payload) & $\sim 300 \mathrm{~kg}$ \\
Wingspan & $5 \mathrm{~m}$ \\
Maximum payload & $\sim 25 \mathrm{~kg}$ \\
Maximum speed & $\sim 250 \mathrm{~km} / \mathrm{h}$ \\
Take-off distance & $<12 \mathrm{~m}$ \\
Climbing slope & $\sim 50^{\circ}$ \\
Rate of turn & $45^{\circ}$ to $60^{\circ}$
\end{tabular}

computer sends the control instructions to the simulation model. After the received commands and data are processed and solved by the model, the simulation computer sends the attitude angle, angular rate, position, and height information to the flight control computer, and the GPS module also sends the signal to the flight control computer. There is no direct connection between the simulation model and the ground measurement and control station, so the flight control computer must be used as the communication bridge. On the simulation platform designed above, a full flight simulation verification of the aircraft was carried out to verify the function of autonomous flight according to a predetermined track. Using the proposed control strategy, the entire rotorcraft flight phase experiences flight conditions such as take-off, climbing, maneuvering, straight flight, and gliding, which can verify the effectiveness of the designed control strategy. Figure 21 shows the complete flight tracked by the simulation model.

For the full-state flight simulation, the data is sorted out within 200 seconds of the initial stage of the rotorcraft simulation. In Figure 22, the proposed control mechanism is working and the aircraft closely maneuvers the predetermined route.

There are three control inputs of the proposed aircraft, namely, throttle, left and right thrust vectors, and blade pitch angle control. Figure 23 presents a response curve of the pitch angle and the forward speed of the aircraft body when only the throttle control input is changed to increase the throttle opening. When the throttle is manipulated to increase the throttle opening, the engine speed will be increased, which in turn produces greater engine thrust. The increased engine thrust will further increase the forward flight speed of the body in the forward component of the body. The rotational speed of the rotor is affected by its pitch angle and relative inflow velocity. Therefore, the increased forward flight speed will significantly increase the rotor speed and the rotor pulling force. If the pitch angle of the rotor is not controlled at this time, then the vertical component of the increased rotor pull will increase the height of the aircraft, and the forward component will hinder the acceleration of the aircraft's forward flight. Therefore, if you want to accelerate the flight at a fixed altitude, you need to increase the throttle opening and coordinate to reduce the pitch angle of the rotor blade.

Figure 24 represents a response curve of the pitch angle and the forward speed of the aircraft body when the pitch angle is increased by controlling the blade pitch only. When the airframe increases the blade pitch under the initial condition of level flight, the increase of the angle of attack will cause the rotor to speed up and the pulling force produced by the rotor to increase. On the one hand, the increase of the rotor pull force will form an upward acceleration in the vertical component, and the height of the aircraft will continue to increase. On the other hand, the component in the forward direction will reduce the forward speed of the aircraft, and the reduced speed, in turn, acts on the rotor, so that the rotational speed and the pulling force of the rotor will be also be reduced. Under this action, the blade angle of attack increases, the flight altitude gradually increases, and the forward flight speed continues to decrease. Finally, the lift and gravity balance and the aircraft body reach a new stable state.

Figure 25 shows a response curve of the pitch angle and the forward speed of the body when only the left and right engine thrust vectors are manipulated in the same direction. The vector thrust engine can deflect up and down in the longitudinal direction and can be used as the longitudinal control amount when the two rotations in the same direction are changed at the same time and will 

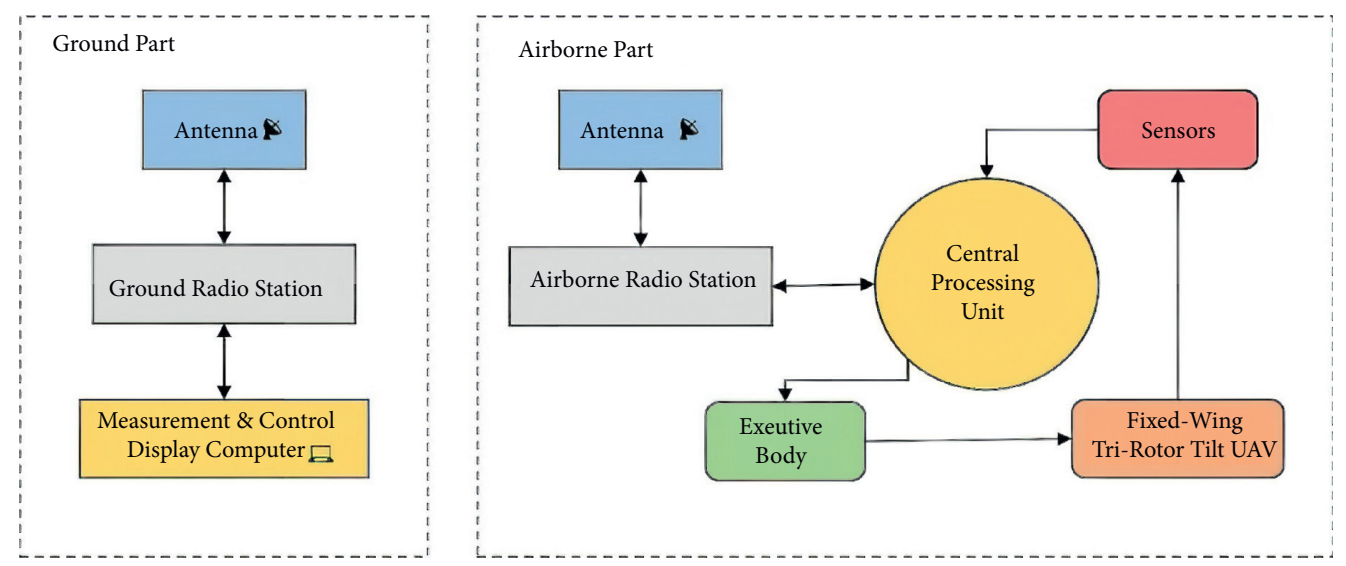

FIgURE 17: The overall framework design of the system.

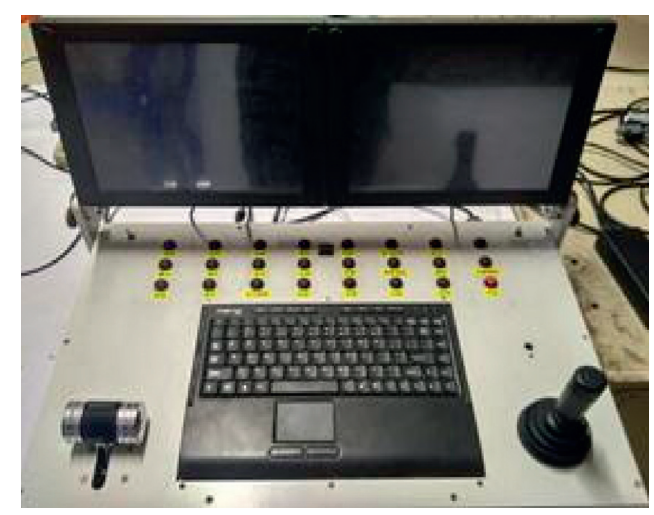

FIGURE 18: Ground measurement and control station.

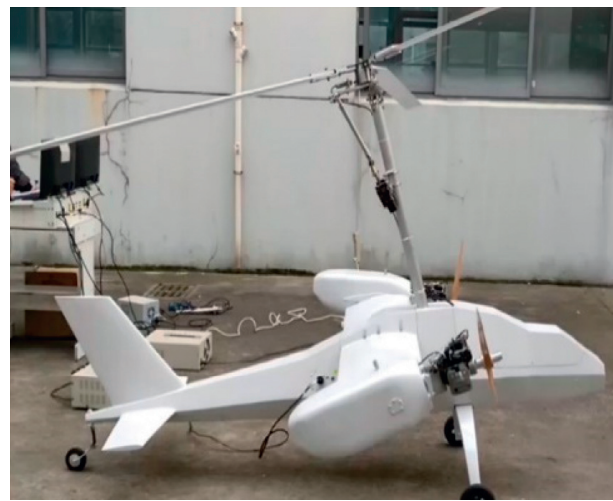

FIgURE 19: Fixed-wing aircraft.

not affect the lateral control. Assuming that the airframe is in a horizontal and straight flight motion at a certain altitude, the left and right engine thrust axis deflection control amounts are simultaneously increased by the same positive value, i.e., the thrust axis deflection upwards at the same time, and the throttle opening remains unchanged. This causes the left and right engine thrust components to decrease in the forward flight direction, while the vertical flight component increases. The increase in the vertical flight component will increase the height of the aircraft, and the reduced forward flight direction component will cause the aircraft to fly forward. The reduction in speed and the reduction in forward speed reduce the rotation speed of the rotor, and the pull of the main rotor continues to decrease. Eventually, the vertical lift of the main rotor and engine vector thrust balances with gravity, and the body reaches a new stable state.

Figure 26 presents the roll angle and roll angular rate. The roll angle responds to the thrust vectors which control the roll of the aircraft. As is apparent in the graph, the roll angle of the plane changes sharply at around midway of flight and then recovers in a few seconds. Now, the angular rate increases when there is an increase in the original angle and decreases when there is a decrease in the original angle. When the roll angle starts to decrease around the $125 \mathrm{~s}$ mark, the angular rate also registers a negative spike around the same time. When the roll angle starts to increase again around the $145 \mathrm{~s}$ time, the angular rate also starts to increase.

Figure 27 shows the responses of the pitch angle and pitch angular rate, respectively. The pitch angle corresponds to the blade pitch which means that when the plane is lifting up, the pitch angle will change, which can be seen in the graph. Now, the angular rate changes when there is a variation in the original angle. Therefore, whenever there is a sharp variation in the pitch angle, we see the subsequent positive or negative spike in the angular rate as well. Minor fluctuations throughout the angular rate are noticed because the pitch angle is never constant. Instead, it keeps hovering between certain values and hence we see the fluctuations in the subsequent graph.

Figure 28 presents the yaw angle and yaw angular rate. As discussed in Section 3, thrust vectors control the yaw of the aircraft. When the thrust vectors move to the left, the aircraft turns left, and when the thrust vectors move to the right, the plane turns right. Yaw is mainly used when the aircraft loses its track because of some obstacle 


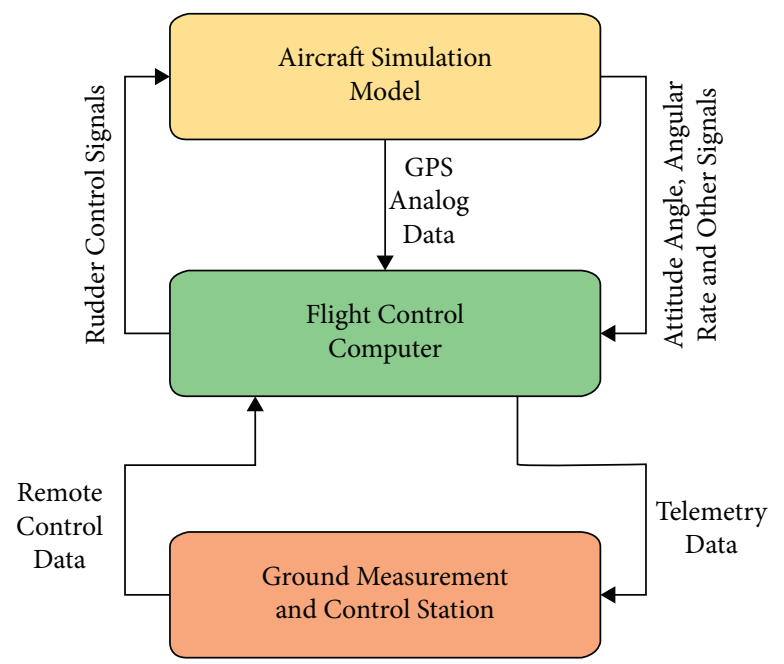

FIGURE 20: Ground semiphysical simulation platform.

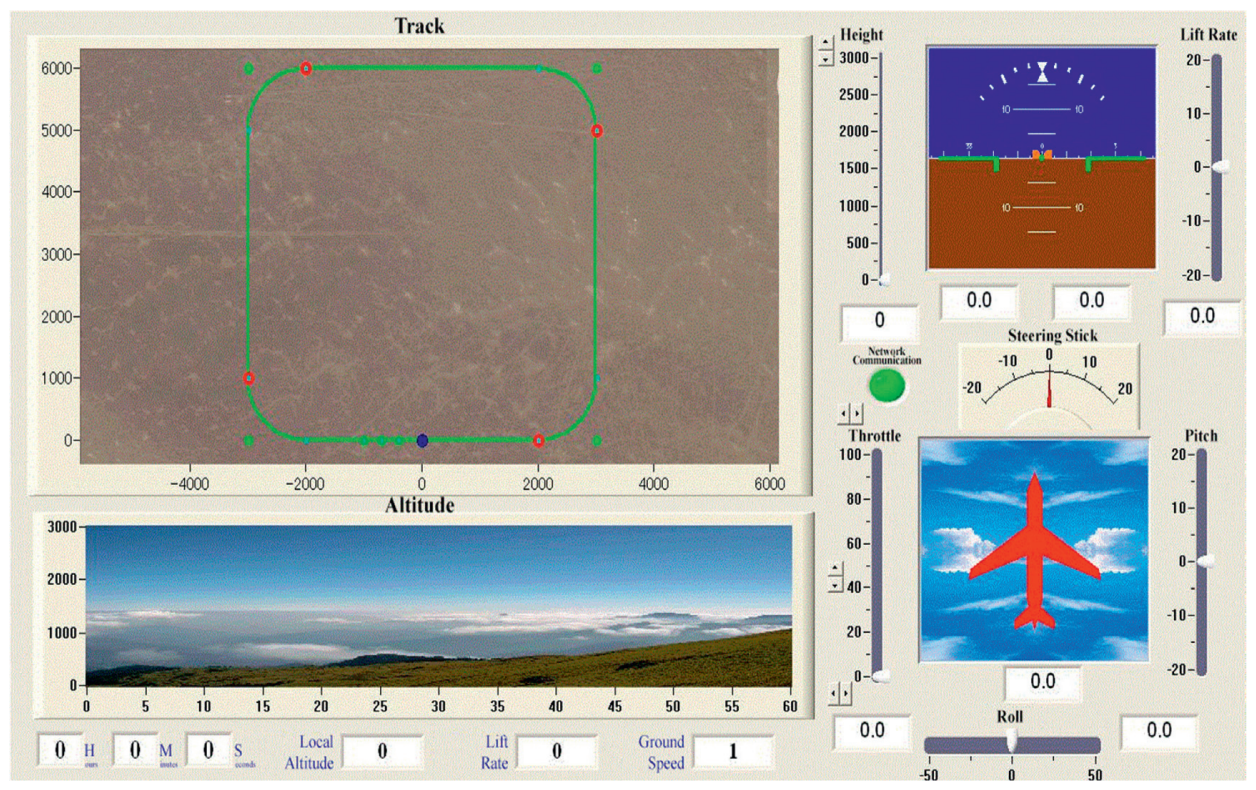

FIgURE 21: Tracking the flight of the aircraft.
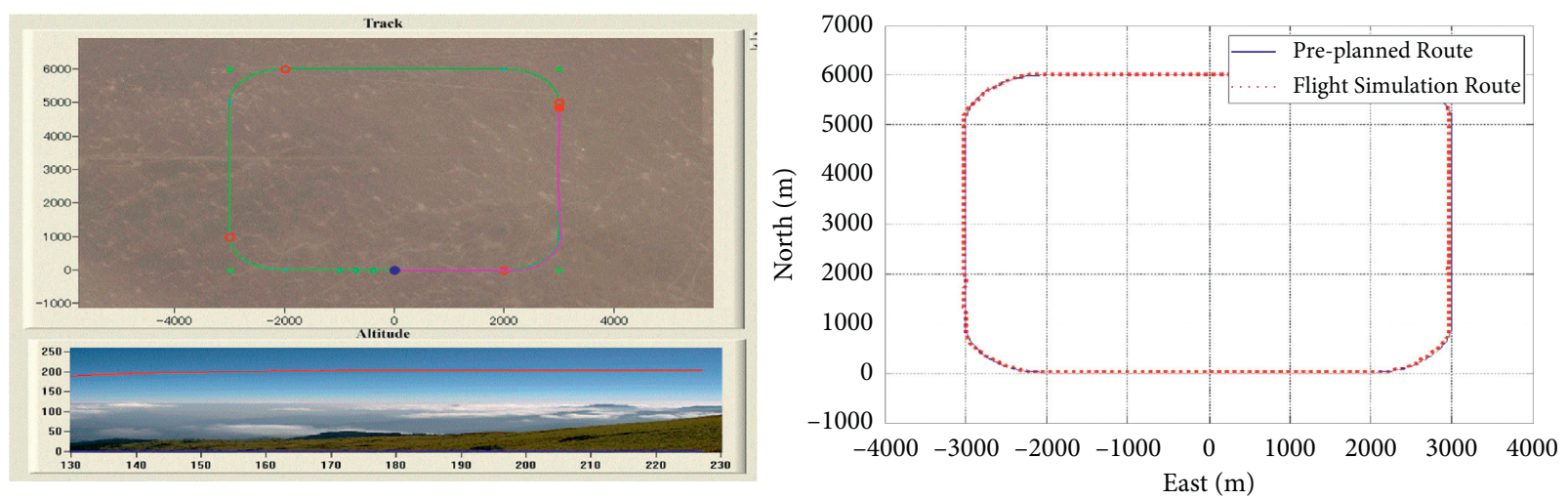

FIGURE 22: Aircraft flight track. 

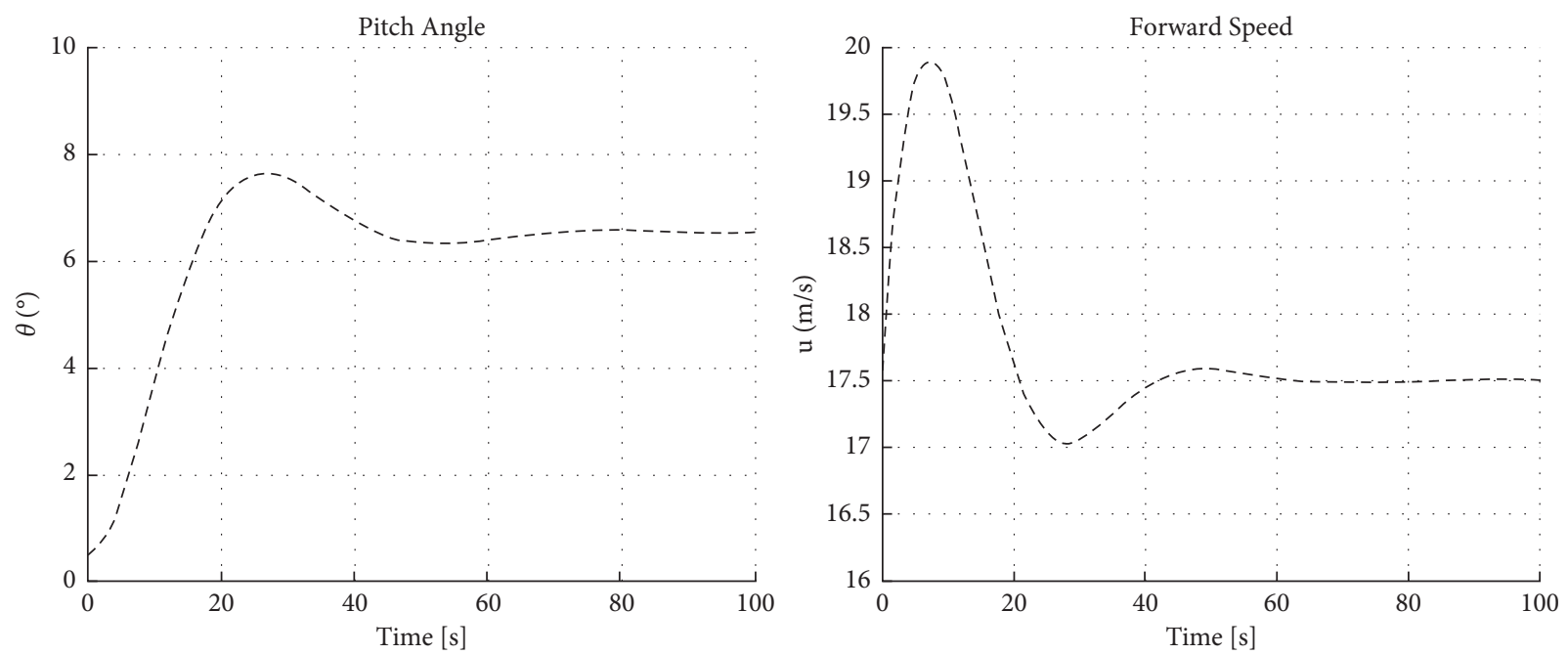

FIGURE 23: Response curve of the throttle control.
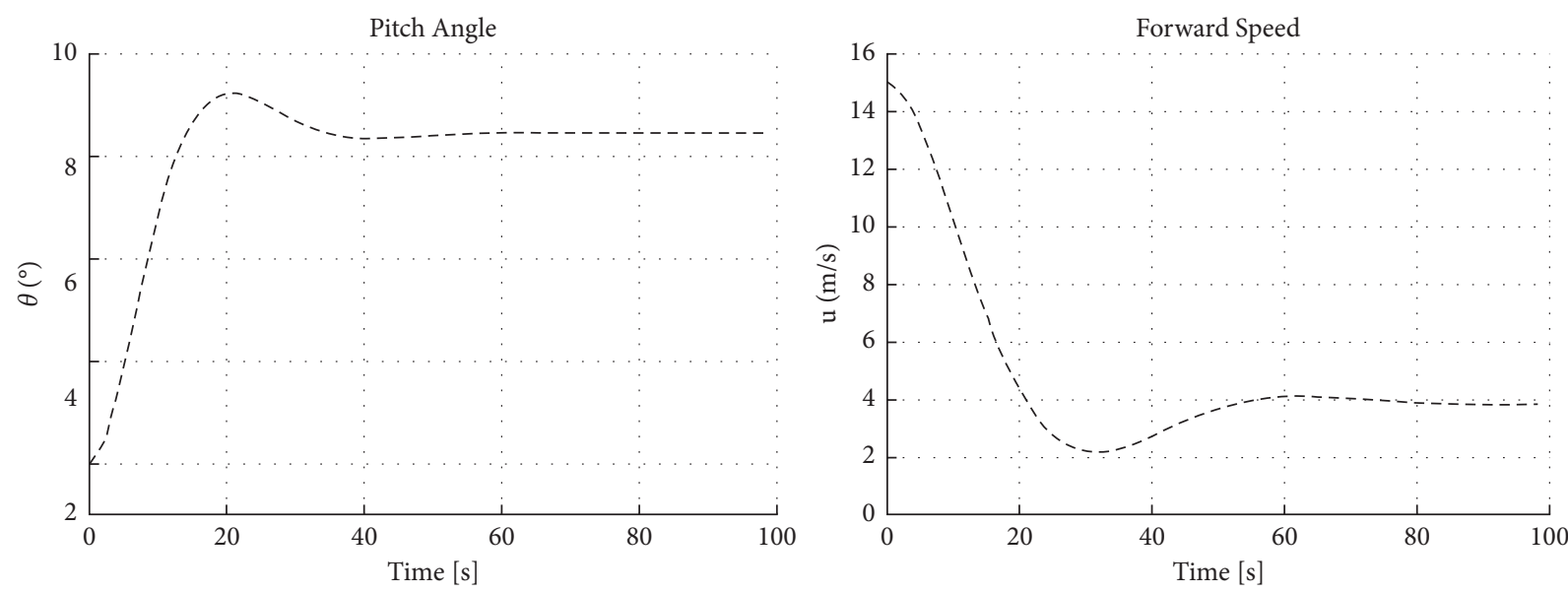

FIGURE 24: Response curve of the blade pitch control.
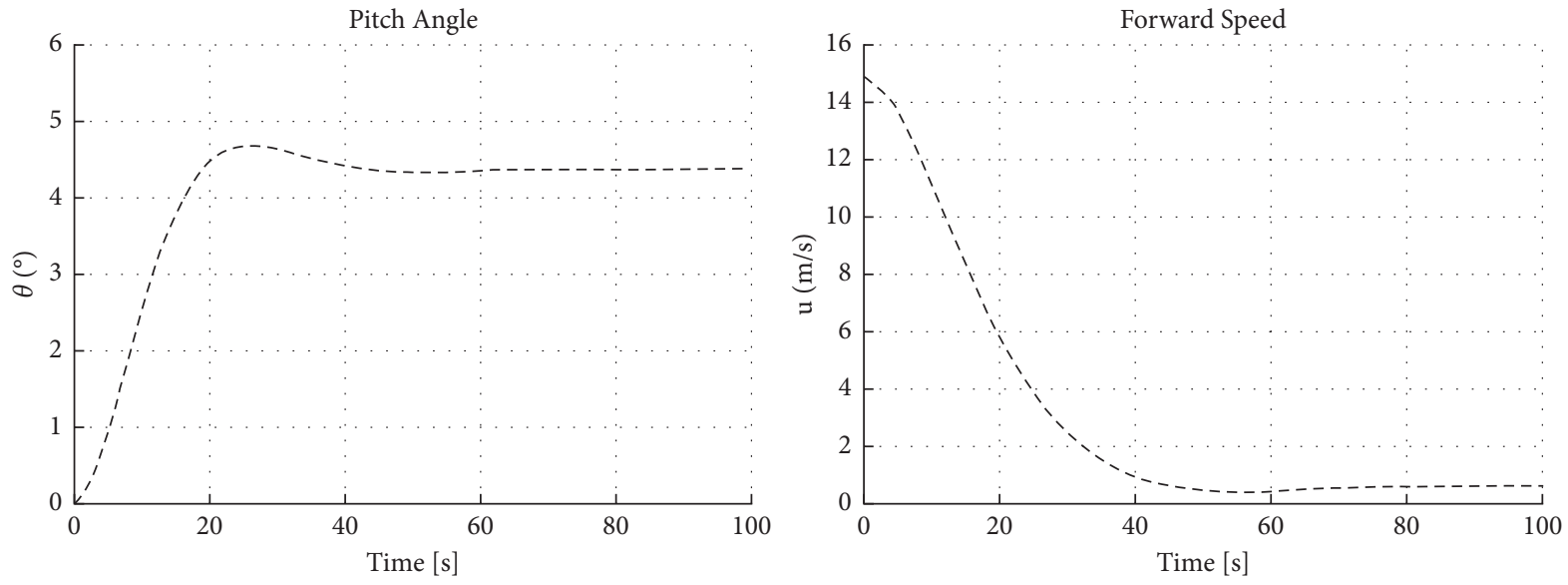

Figure 25: Response curve of thrust vectors of left and right engine. 

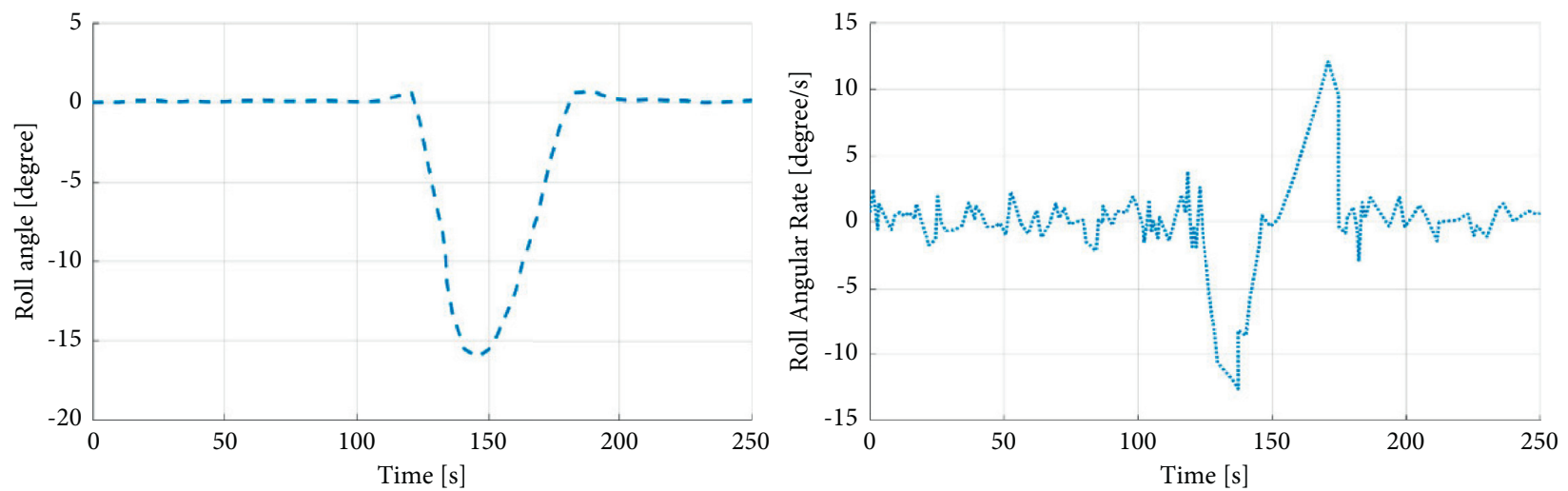

Figure 26: Roll angle and roll angular rates.
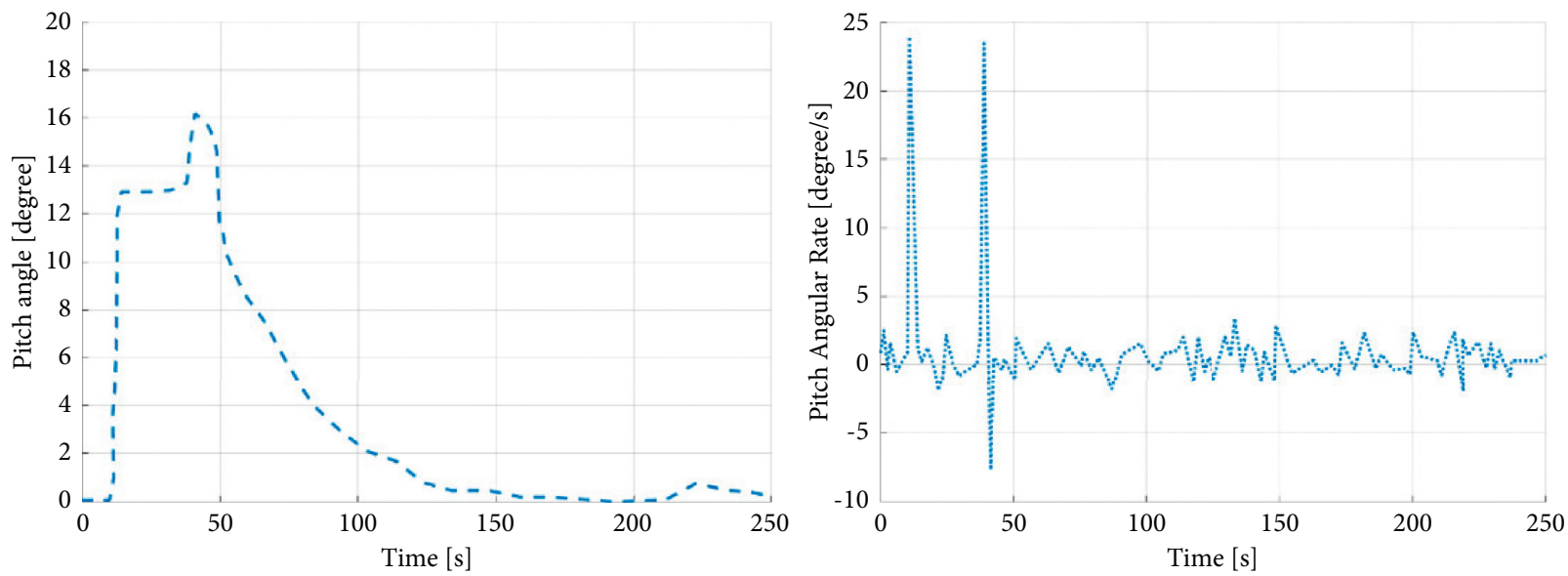

FIgURE 27: Pitch angle and pitch angular rate.
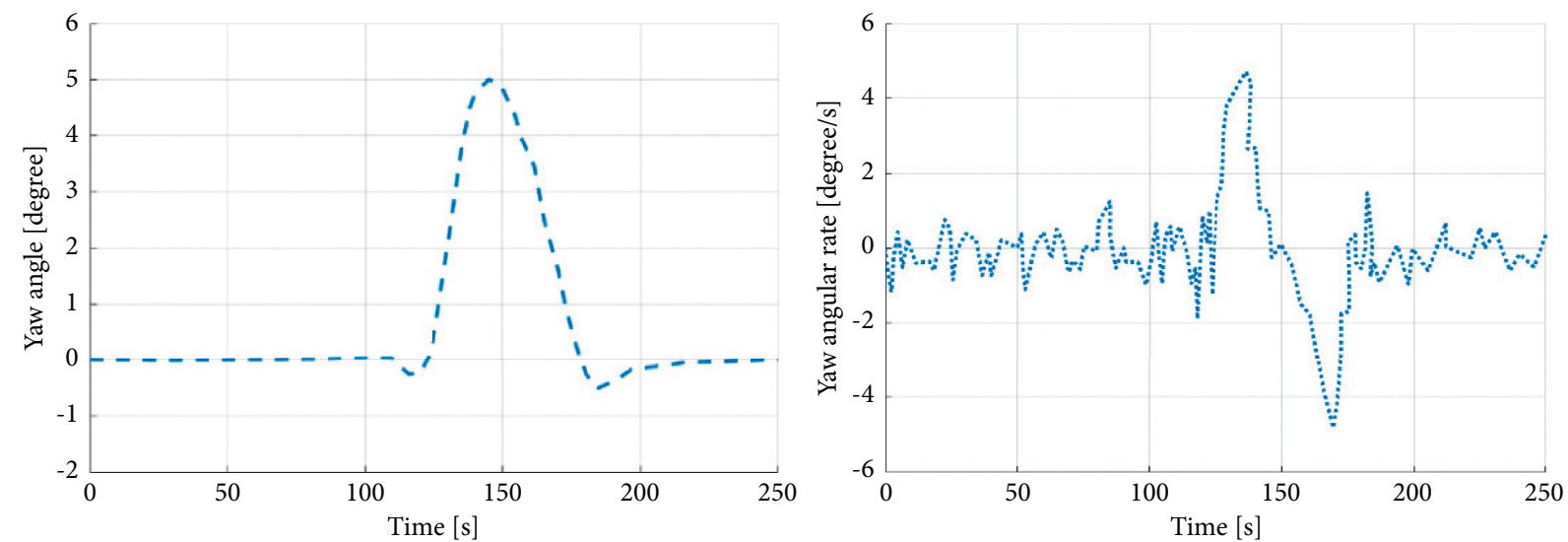

FIgURe 28: Yaw angle and yaw angular rate.

or strong winds. Hence, there is an insignificant variation in the yaw angle of about $5^{\circ}$ around $150 \mathrm{~s}$. The corresponding angular rate registers even this minute change and demonstrates the increase and then decrease in the yaw angle accordingly.
Figure 29 offers the velocity and the altitude of the aircraft. The aircraft slightly picks up the pace and then maintains that speed over time. Similar is the case with the altitude. It gradually increases its altitude and then maintains it for the rest of the flight. 

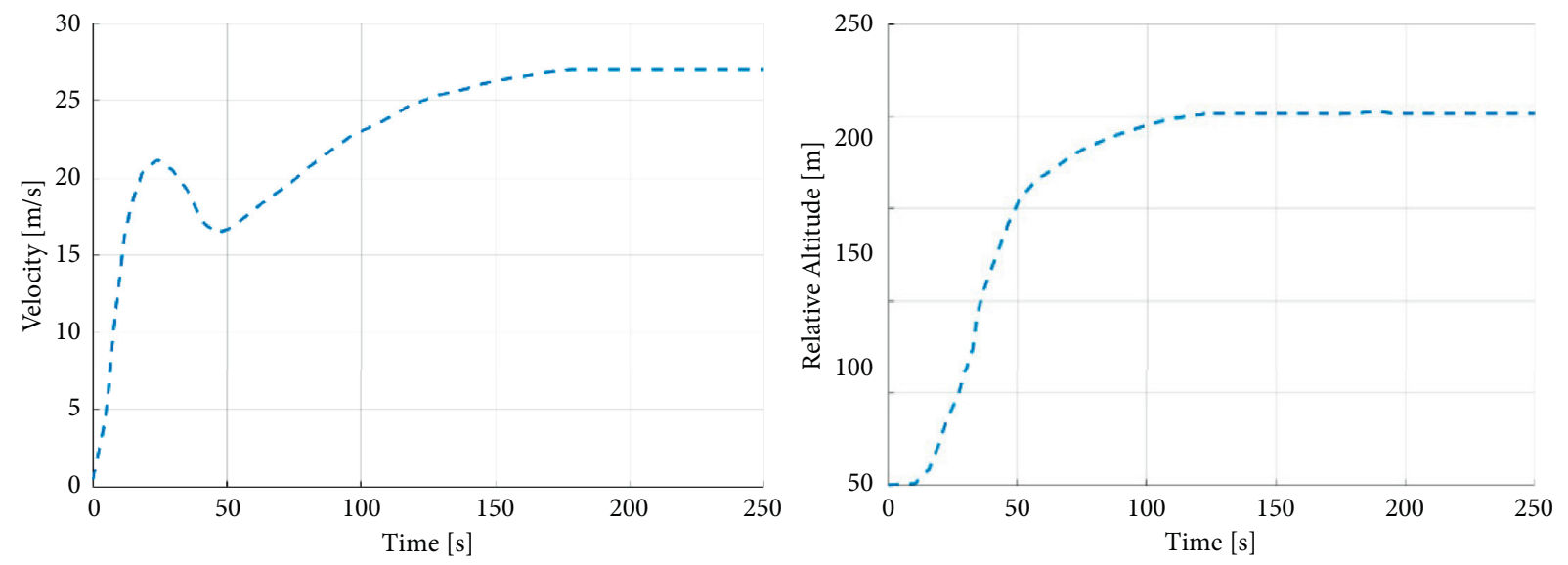

FIgURE 29: Velocity and altitude.

\section{Conclusion}

This research article gives guidance, navigation, and control algorithm for a new and novel fixed-wing aircraft based on the hybrid model. The designing of the mathematical model of the proposed work has been characterized by the hybrid strategy of PID and Neural Network approach along with maneuvering. However, the attitude, altitude, speed, turns, and take-off control of the fixed-wing UAV are studied, respectively. Afterward, a GPS module is used in the flight control strategy. The flight control system of the rotor aircraft is implemented and set up the semiphysical simulation platform and carried out the simulations. The simulation results that are HWIL based verified the effectiveness and stability of our proposed technique. We intend to apply our designed method to the hardware and test the application of our designed method in a real-life scenario.

\section{Data Availability}

All the data used to support the findings of this study are included within the article.

\section{Conflicts of Interest}

The authors declare that they have no conflicts of interest.

\section{Acknowledgments}

This work was supported by Taif University Researchers Supporting Project number TURSP-2020/292, Taif University, Taif, Saudi Arabia. Also, this research was funded by the Deanship of Scientific Research at Princess Nourah Bint Abdulrahman University through the Fast-track Research Funding Program.

\section{References}

[1] H. Shakhatreh, A. H. Sawalmeh, A. Al-Fuqaha et al., "Unmanned aerial vehicles (uavs): a survey on civil applications and key research challenges," IEEE Access, vol. 7, pp. 48572-48634, 2019.
[2] S. H. Alsamhi, O. Ma, M. S. Ansari, and F. A. Almalki, "Survey on collaborative smart drones and internet of things for improving smartness of smart cities," IEEE Access, vol. 7, pp. 128125-128152, 2019.

[3] D. O. Wheeler, D. P. Koch, J. S. Jackson et al., "Relative navigation of autonomous GPS-degraded micro air vehicles," Autonomous Robots, vol. 44, no. 5, pp. 811-830, 2020.

[4] B. J. Brelje and J. R. R. A. Martins, "Electric, hybrid, and turboelectric fixed-wing aircraft: a review of concepts, models, and design approaches," Progress in Aerospace Sciences, vol. 104, pp. 1-19, 2019.

[5] G. Flores and R. Lozano, "Transition flight control of the quadtilting rotor convertible MAV," in Proceedings of the 2013 International Conference on Unmanned Aircraft Systems (ICUAS), Atlanta, GA, USA, May 2013.

[6] Ö. Dündar, M. Bilici, and T. Ünler, "Design and performance analyses of a fixed wing battery VTOL UAV," Engineering Science and Technology, an International Journal, vol. 23, no. 5, pp. 1182-1193, 2020.

[7] D. Chabot, "Trends in drone research and applications as thejournal of unmanned vehicle systemsturns five," Journal of Unmanned Vehicle Systems, vol. 6, pp. vi-xv, 2018.

[8] J. Leishman, Principles of Helicopter Aerodynamics, Cambridge University Press, Cambridge, UK, 2017.

[9] H. Duda and I. Pruter, "Flight performance of lightweight gyroplanes," in Proceedings of the 28th International Congress of the Aeronautical Sciences, Brisbane, Australia, August 2012.

[10] J. G. Leishman, "Development of the autogiro: a technical perspective," Journal of Aircraft, vol. 41, no. 4, pp. 765-781, 2004.

[11] R. V. Petrescu, R. Aversa, B. Akash et al., "About helicopters," Journal of Aircraft and Spacecraft Technology, vol. 1, no. 3, pp. 204-223, 2017.

[12] B. H. Charnov, From Autogiro to Gyroplane: The Amazing Survival of an Aviation Technology, Praeger, Santa Barbara, CF, USA, 2003.

[13] K. S. Brentner, P. J. Morris, and L. V. Lopes, "A method for predicting the noise of A tip-jet driven rotor," Journal of the American Helicopter Society, vol. 59, no. 3, pp. 1-10, 2014.

[14] M. W. Floros and W. Johnson, "Performance analysis of the slowed-rotor compound helicopter configuration," Journal of the American Helicopter Society, vol. 54, no. 2, pp. 220022200212, 2009.

[15] X. Wang and H. Lin, "Design and control for rotor-fixed wing hybrid aircraft," Proceedings of the Institution of Mechanical 
Engineers-Part G: Journal of Aerospace Engineering, vol. 225, no. 7, pp. 831-847, 2011.

[16] J. Pravitra and E. Johnson, "Adaptive control for attitude match station-keeping and landing of A fixed-wing UAV onto A maneuvering platform," in Proceedings of the AIAA Scitech 2020 Forum, Orlando, FL, USA, January 2020.

[17] K.-J. Nam, J. Joung, and D. Har, "Tri-copter UAV with individually tilted main wings for flight maneuvers," IEEE Access, vol. 8, pp. 46753-46772, 2020.

[18] H. Chao, Y. Cao, and Y. Chen, "Autopilots for small unmanned aerial vehicles: a survey," International Journal of Control, Automation and Systems, vol. 8, no. 1, pp. 36-44, 2010.

[19] J. C. Nash and P. A. Laplante, "Real-time system to control aircraft propeller pitch," Journal of Aerospace Computing, Information, and Communication, vol. 1, no. 4, pp. 198-212, 2004.

[20] R. Samar and A. Rehman, "Autonomous terrain-following for unmanned air vehicles," Mechatronics, vol. 21, no. 5, pp. 844-860, 2011.

[21] A. Redei and S. Dascalu, "A method for handling multi axis input for a motion based flight simulator," in Proceedings of the 27th International Conference on Software and Data Engineering 2018, New Orleans, LA, USA, October 2018.

[22] H. González-Jorge, J. Martínez-Sánchez, M. Bueno, and a. P. Arias, "Unmanned aerial systems for civil applications: a review," Drones, vol. 1, no. 1, p. 2, 2017.

[23] D. Hull, Fundamentals of Airplane Flight Mechanics, Springer, Berlin, Germany, 2010.

[24] X. Ge, F. Yang, and Q.-L. Han, "Distributed networked control systems: a brief overview," Information Sciences, vol. 380 , pp. 117-131, 2017. 